\title{
O Bituario
}

\section{Profesor Dr. Roque Kraljevic Orlandini (1911-2009)}

\author{
A tribute to Roque O. Kraljevic, M.D. \\ (1911-2009), Master of Internal \\ Medicine and Infectology
}

$\mathrm{E}^{1}$ Dr. Roque Kraljevic nació en Iquique el 2 de enero de 1911. Sus estudios primarios y secundarios los realizó en Valparaíso. Graduado Médico-Cirujano en la Universidad de Chile, en 1937, su tesis versó sobre "La acción anti-estreptocóccica de la sulfacrisoidina en varias especies animales", aprobada con distinción máxima. Se perfeccionó en cátedras universitarias de bacteriología, inmunología y enfermedades infecciosas en Chile y Argentina (1942). Pocos años después, fue designado Jefe de Clínica en el Servicio de Enfermedades Infecciosas del Hospital Barros Luco, a cargo del eminente médico y salubrista Dr. Abraham Horwitz y cuyo jefe era el Dr. Lucio Córdova. En 1944, Kraljevic junto con Horwitz, crearon un curso sobre Clínica de las Enfermedades Infecciosas para salubristas en el programa de postgrado de la Escuela de Salud Pública de la Universidad de Chile, que era una novedad en Chile y en el extranjero. En 1946 el Dr. José Manuel Balmaceda, Profesor de la Facultad de Medicina de la Pontificia Universidad Católica de Chile, le solicitó a los Drs. Horwitz y Kraljevic dictar un curso de Enfermedades Infecciosas a los estudiantes de $5^{0}$ año, integrado al programa de Medicina Interna, lo que fue un inicio formal de la enseñanza de esta disciplina en el pregrado de las Escuelas de Medicina.

En 1950 se inauguró el Pabellón de Enfermedades Infecciosas en los recintos del Hospital Barros Luco bajo la responsabilidad de los Drs. Abraham Horwitz, Roque Kraljevic y José Perroni, lo que tendría decisiva importancia en su carrera profesional. El Dr. Kraljevic fue designado Jefe de

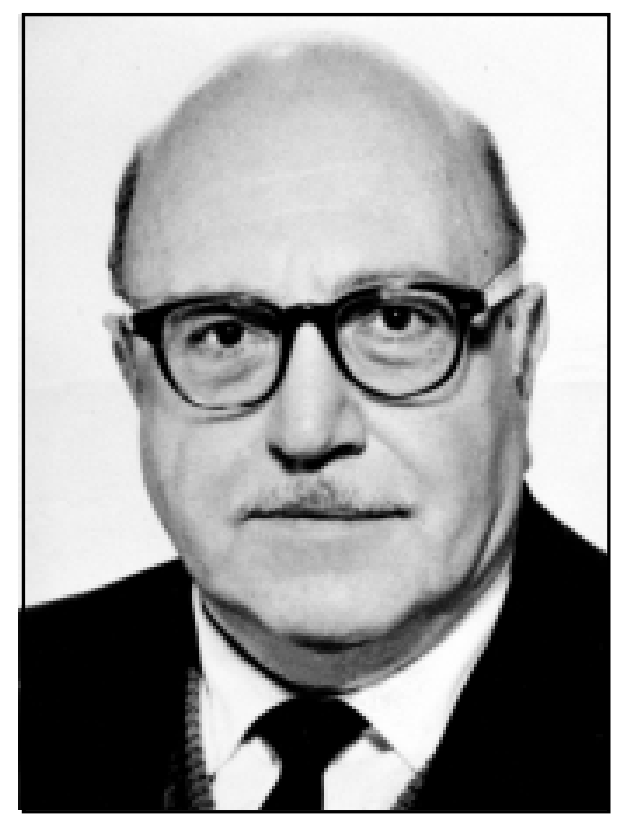

Profesor Dr. Roque Kraljevic Orlandini (1911-2009).

ese Servicio, desplegando allí todas sus capacidades docentes, de investigación y administrativas durante casi 20 años. Era, en verdad, un servicio modelo y único en el país, tanto por su moderna estructura arquitectónica, adaptada a la naturaleza de las enfermedades infectocontagiosas, como por el rigor de su actividad clínica. Generaciones de estudiantes de las Facultades de Medicina de la Universidad de Chile y Católica y alumnas de las Escuelas de Enfermería, realizaban el curso de 
Enfermedades Infecciosas en ese recinto, recibiendo sus enseñanzas y realizando actividades prácticas con él y sus ayudantes, bajo rigurosas normas técnicas clínicas de asepsia.

Kraljevic y su grupo hicieron, además, importantes y numerosas investigaciones sobre enfermedades infecciosas, particularmente sobre el diagnóstico, tratamiento y pronóstico de la Fiebre Tifoidea, de alta prevalencia en aquella época, ilustrando a todos los médicos para un correcto manejo de las enfermedades infectocontagiosas.

Dado el grado de desarrollo y la importancia que alcanzó esta especialidad, y por empeño del Dr. Kraljevic, el Pabellón se transformó en 1963 en un Hospital de Enfermedades Infecciosas, con independencia administrativa y presupuestaria. Demostrando su generosidad y lealtad, el Dr. Kralejvic propuso que llevara el nombre del Dr. Lucio Córdova. Kraljevic dirigió brillantemente ese hospital hasta su jubilación en 1969. Posteriormente y hasta avanzada edad, se desempeñó en el Servicio Médico y Dental de los Estudiantes de la Universidad de Chile.

Su monografía «El tifus murino y otras Rickettsiasis», le sirvió de tesis para optar al título de Profesor Extraordinario de Enfermedades Infecciosas de la Universidad de Chile (1957). Alcanzó la jerarquía de Profesor Titular en las Universidades de Chile y Pontificia Universidad Católica de Chile y la posición de Presidente de la Sociedad Médica de Santiago (1959-1961). Su trayectoria de servicio público fue sobresaliente, lo que fue ampliamente reconocido por sus pares. De ello dan testimonio las numerosas distinciones que recibió: Profesor Emérito de la Universidad de Chile (1961), Miembro Académico y Grado Honorífico Académico de la Pontificia Universidad Católica de Chile (1962), Socio Honorario de la Sociedad Médica de Santiago (1969), Miembro Honorario del Servicio Nacional de Salud (1974), Maestro de la Medicina Interna (1984), Miembro Honorario de la Sociedad Chilena de Infectología (1993), Maestro de la Infectología Latinoamericana (1993), Gran Maestro de la Sociedad de Infectología (1997) y el Premio Sociedades Médicas de Chile a la Excelencia (1998), un galardón precursor del Premio Nacional de Medicina. En razón de su brillante carrera profesional y docente, la Academia Chilena de Medicina lo nombró Miembro Honorario en 1988.

El Dr. Kraljevic falleció en Santiago el 12 de enero de 2009 a los 98 años de edad.

Este Maestro de la Medicina, pionero de la creación y desarrollo de la especialidad de Infectología en Chile, era un hombre de contextura gruesa, alegre, bondadoso y cálido que amaba su profesión y la enseñanza y prestó grandes servicios a la medicina chilena. Hijo agradecido, mostraba un gran reconocimiento y cariño por sus antepasados croatas, lo que solía hacer presente en nuestros ocasionales encuentros. Para mí, que fui su alumno y me dispensó su cariño y amistad, es un deber de gratitud hacer un recuerdo de su distinguida trayectoria.

\section{Dr. Alejandro Goic G.}

Presidente, Academia Chilena de Medicina 